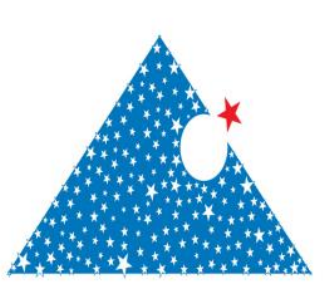

\title{
Mimarlıkta Sesli Komut Teknolojisinin Kullanımı
}

\author{
Mehmet TEKİN $^{1 a}$, Erdem KÖYMEN ${ }^{2 b}$ \\ ${ }^{1}$ Sabahattin Zaim Üniversitesi, Fen Bilimleri Enstitüsü, Mimarlık Yüksek Lisans Programı, İstanbul/Türkiye; \\ ${ }^{2}$ Sabahattin Zaim Üniversitesi, Mühendislik ve Doğa Bilimleri Fakültesi, Mimarlık Bölümü, İstanbul, Türkiye; \\ mimarmehmettekin@gmail.com
}

Received/Geliş: 04.08.2020

Accepted/Kabul: 23.09.2020

\begin{abstract}
Öz: Dünyada teknoloji her gün gelişmekte ve bunun sonucu olarak insan yaşamını kolaylaştırıcı birçok yazılımsal ve donanımsal yenilikler ortaya çıkmaktadır. Bu yeniliklerin en belirginlerinden biri sesli komutlar ile çalışan sesli asistanlardır. Bu asistanlar yıllardır kullanılmakta olan dokunmaya dayalı etkileşim teknolojisine yeni ve hızlı bir alternatif oluşturmaktadır. Bu çalışmanın amacı, pek çok alanda kullanılan sesli asistanların mimarlığın çeşitli dallarında mevcut olan az sayıdaki kullanımlarına değinmek ve bu kullanımın genişletilebilmesi adına öneriler ortaya koymaktır. Bu bağlamda önce sesli komutların genel kullanım alanları ve kullanıcılara yaşatılan deneyimler ortaya koyulmuştur. Daha sonra sesli komutların mimarlığın farklı alanlarındaki kullanımını daha iyi incelemek adına mimarlık, beş alt dalı olacak şekilde şematize edilmiş ve sesli komutların bu alt dallardaki kullanımlarından örneklere değinilmiştir. Son olarak sesli asistanların mimarlık alanındaki kullanımlarının daha çeşitli ve verimli hale getirilebilmesi adına birtakım öneriler sunulmuştur. Bu çalışmanın, sesli asistan teknolojisine dikkat çekerek mimarlığın tüm süreçlerine katkı sağlayacak yeni bir bakış açısını mimarlık dünyasına kazandıracağı öngörülmektedir.
\end{abstract}

Anahtar kelimeler: Mimarlık; sesli komut; sesli asistan; teknoloji

\section{Use of Voice Command Technology in Architecture}

\begin{abstract}
Technology is developing every day in the world and as a result, many software and hardware innovations are emerging that facilitate human life. One of the most obvious of these innovations is the voice assistants working with voice commands. These assistants are a new and fast alternative to touch-based interaction technology that has been in use for years. Voice assistants, which are watched in many fields, are almost not encountered in the field of architecture. Therefore, the subject has been found worthy of study as an original and new research area for architecture. The aim of this study is to investigate the potential use of voice assistants in architecture and to make suggestions in order to become widespread in the field of architecture. In this context, the general usage areas of voice commands are first introduced, and the experiences of the user are examined. Afterwards, architecture is divided into five subbranches and voice command technology is examined in terms of these sub branches. Finally, various suggestions are presented to draw attention to the potential contributions that voice assistants can make to the field of architecture. It is anticipated that this study will draw attention to the voice assistant technology and bring a new perspective to the world of architecture that will contribute to all processes of architecture.
\end{abstract}

Keywords: Architecture; voice command; voice assistant; technology

\section{Giriş}

21.yy'da teknoloji her geçen gün biraz daha gelişmekte ve şaşırtıcı noktalara ulaşmaktadır. Bu gelişim pek çok alan gibi insan hayatının büyük bir parçasını kapsayan mimarlık alanında da görülmektedir. Sürekli değişen ve gelişen yapım teknikleri ile yapılar daha kısa sürelerde üretilebilmektedir. Yapı üretim süreçlerinde gerçekleşen bu hızlanma, tasarım sürecinde de buna 
paralel bir hızlanma gerekliliğini beraberinde getirmiştir. Her gün bir yenisi ile tanıştığımız mimari çizim programları sayesinde sadece tuşlara ya da bir ekrana dokunarak eskiden birçok zahmetle tamamlanabilen tasarım ve çizim süreçleri çok kısa sürelerde bitirilebilmektedir.

Bununla beraber çağımızda her yenilik ve gelişimin sürekli daha iyisine doğru bir değişimi gerektirdiği de açıktır. Bu değişim gerekliliğinin bir sonucu olarak, çoğu alanda dokunmatik etkileşimin yerini sesli asistanlar almaktadır. Bu asistanlar bankacılıktan telekomünikasyona, eğitimden yazılıma kadar birçok alanda kullanılmaya başlanmış ve artarak yayılmaya ve gelişmeye devam etmektedir.

\subsection{Sesli Asistanlar}

Sanal asistanlar (virtual assistants-VAs) daha önce insanlar tarafindan yapılan birtakım yazılımsal basit işleri veya hizmetleri, kullanıcılarının soru ve talepleri ile gerçekleştiren yazılımlardır. Genellikle chatbot kavramı ile aynı anlamda kullanılırlar ancak sanal asistanlar daha geniş bir alanda hizmet verir. Sanal asistanlar kullanıcı ile yazı veya konuşma yoluyla etkileşim kurabilirler [1].

Sesli asistan teknolojisinin bilgisayar vb. teknoloji ürünlerinin dokunmatik kullanım şekline farklı bir alternatif oluşturduğu görülmektedir. Bilgisayar teknolojilerinin ilk kullanımlarındaki tuşlu etkileşimin yerini zamanla dokunmatik ekranlar almaya başlamıştır. Sesli asistanların da teknolojik cihazlarla etkileşime girmenin yeni ve orijinal bir yöntemi olarak birçok dijital yazılımda kullanılmakta olduğu ve bu asistanların kullanıcılarına birçok kolaylıkla birlikte yeni deneyimler sunduğu görülmektedir.

\subsection{Sesli Asistanların Kullanım Alanları}

Sanal asistanlar kullanıcılarının seyahat saatleri veya hava durumu gibi sorularına yanıt verme, günlük yaşamda alarm kurma, müzik çalma vb. basit komutları yerine getirme, kurumların müşteri hizmetleri servisleri gibi fonksiyonlar için kullanılmaktadır. $\mathrm{Bu}$ amaçla kullanılan asistanlar bankacılık, e-ticaret, sağlık ve hava yolları asistanları olarak yaygınlaşmaktadır.

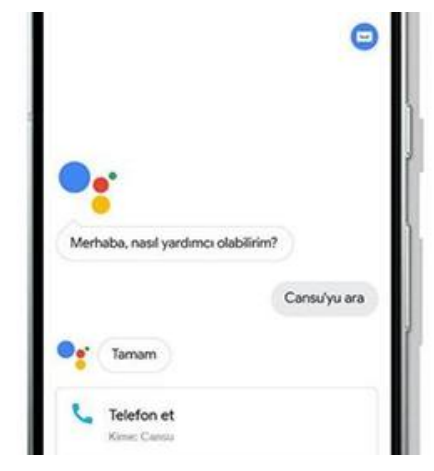

(a)

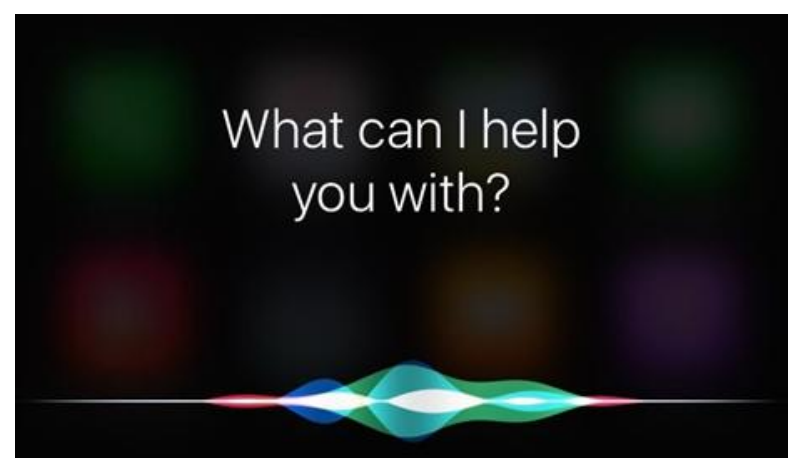

(b)

Şekil 1. a) Google Assistant'1n ara yüzü. b) Siri'nin ara yüzü.

Yapılan saha araştırmasında sesli asistanların çeşitli yazılımlar, elektronik ürünler, binek araçlar, bilgisayar oyunları gibi birçok kullanımı görülmüştür. Örneğin bir bilgisayar oyununda klavye ve fare etkileşimiyle entegre olarak kullanılmıştır. Burada kullanıcının bazı komutları mevcut donanımlarla, bazılarını ise sesle verdiği, dolayısıyla kullanıcıya kolaylık sağladığı ve deneyimsel farklılıklar yaşattığı görülmüştür (Şekil 2). 


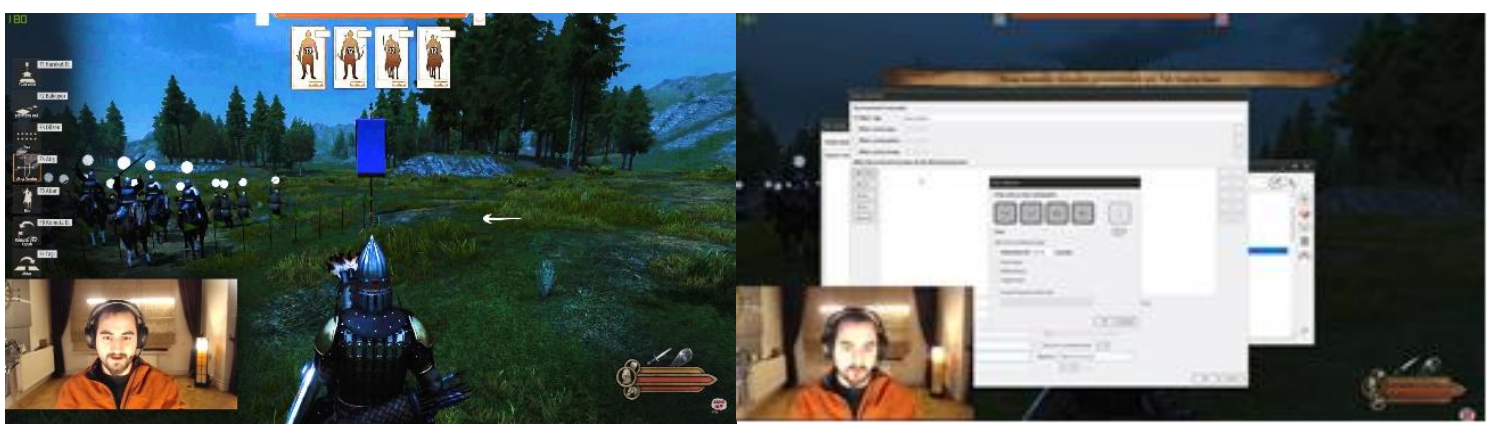

Şekil 2. Mount and Blade adlı oyunda sesli komut kullanımı [2].

Yeni nesil otomobillerde sürüş esnasında sürücünün dikkatinin dağılmaması için bazı sistemler ses ile kontrol edilebilmektedir [3]. Nands Assistant adlı başka bir yazılım ise görme engelliler için tasarlanmıştır ve bilgisayarla sadece ses ile etkileşim kurmayı sağlamaktadır [4]. Ayrıca TV üretimi yapan bir teknoloji firmasının ürünlerinden birinde ses komutlarının kullanımına rastlanmıştır [5]. Bunların yanında sesli komutlardan, farklı amaçlara hizmet edecek şekilde de birçok alanda yararlanıldığı bilinmektedir. Tüm bu örneklere bakıldığında bu teknolojinin dijital etkileşimdeki kullanımının sürekli genişlediği görülebilir.

Yukarıda incelenen örneklerin yanında makalenin asıl araştırma alanı olan mimarlıkta da sesli asistanların kullanımına rastlanmış, bu kullanımlara gelecek konu başlıklarının altında değinilmiştir.

\section{Mimarlıkta Sesli Komut Teknolojisi Kullanımı}

Mimarlık bir bilim ve sanat olarak, barınmaya ihtiyaç duyan insanoğlunun dünyada var olduğu ilk zamanlardan bu yana gelişerek ve değişerek süregelmiş bir olgudur. Tekniğin ve sanatın gelişmediği zamanlarda yapılan derme çatma barınaklar, zamanla tekniğin ve estetiğin daha fazla görüldüğü yapılara doğru bir değişim geçirmiştir. İnsanlığın kendini şekil ve çizgilerle ifade etmeye başlamasıyla kullanımı ortaya çıkan el çizimlerine zamanla daha ölçekli eskizler, teknik detaylar ve maketler eklenmiştir. Buna paralel olarak yapım ve uygulama teknolojileri de sürekli daha pratiğe ve hızlıya doğru bir gelişim göstermiştir.

Bu süreçler boyunca mimarlık, ürünü birçok alt süreçten geçirilerek ortaya koyulan bir bilim dalı olmuştur ve daha nitelikli eserler ancak bu süreçlerin tamamının birlikte gelişebilmesiyle ortaya çıkabilmiştir. Mimarlık ürününün oluşumu için geçilmesi gereken bu süreçlerin hepsi içlerinde farklı karakterlerde alt süreçler ve unsurlar barındırmaktadır. Mimarlık pratiği için; tasarlama, tasarımın uygulanması için gerekli bilgiyi üretme, tasarlananı anlatma ve uygulama etkinliği denilebilir[6]. Tasarımı yapan mimarın eğitimi ve uygulaması tamamlanan mimari ürünün kullanım sürecini de bu pratiğin içine kattığımızda mimari bir ürünün oluşumunun uzun soluklu bir süreç içerdiği görülmektedir(Şekil 3). Bu uzun süreçte birçok disiplin mimari ürünün oluşumu için bir arada çalışmaktadır. Ve her disiplin özelleştiği çalışma alanına göre gerçekleşen teknolojik gelişmelerden faydalanmaktadır. Sesli veya sanal asistanların ise iş verimini ve konforunu artıracak potansiyele sahip olduğu ve tüm bu disiplinlerin tamamına birden katk1 sağlayacağı öngörülmektedir.

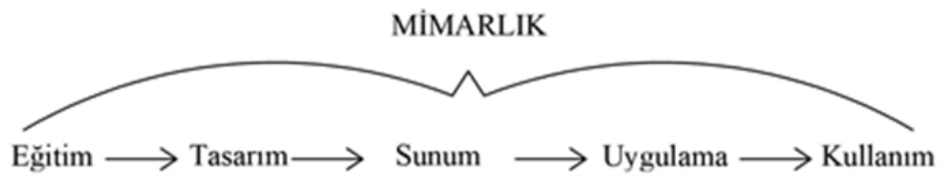

Şekil 3. Mimarlıkta ürün oluşumunun genel süreci. 
Mimarın eğitimi ile başlayan bu süreç, eğitimini tamamlamış ve mimar olarak tanımlanmaya hak kazanmış kişinin gerçekleştirdiği tasarım üzerinden devam etmektedir. Daha sonra bunu tasarlanmış mimari ürünün potansiyel müşterilere sunumu ve pazarlanması takip etmektedir. Sunum ve pazarlama sürecinden başarı ile geçmiş ürünün uygulama safhasına geçilmekte, tasarım kâğıt ve dijitalden gerçek bir objeye dönüştürülmektedir. Mimari ürünün son aşaması ve amacı ise kullanıcı ve izleyicilerine yaşattığı mekânsal konfor ve görsel deneyim olmaktadır. Görüldüğü üzere sürecin tüm aşamaları birbirine bağlıdır. Bu nedenle çalışmada mimarlık ve mimari ürün kavramları bu alt başlıklara bölünmüş ve sesli asistanların her alt başlığa olan veya olabilecek faydaları ayrı ayrı incelenmiştir.

Yapılan araştırmada, çok geniş tasarım ve uygulama alanları ve pratikleri olmasına karşın mimarlıkta sesli asistanların yaygın kullanımına rastlanmamıştır. $\mathrm{Bu}$ nedenle başlıklar altında sesli asistanların kullanımlarının sınırlı sayıdaki örneklerine değinilmiştir. Bununla beraber başka alanlarda kullanıldığı görülen fakat benzer amaçlara hizmet edebilecek potansiyele sahip kullanımlar üzerinden birtakım öngörülerde bulunulmuştur. $\mathrm{Bu}$ öngörüler ile sesli asistanların farklı alanlardaki kullanımlarının bu alanlardaki iş verimine olan katkılarına dikkat çekmek ve böylece bu asistanların mimarlıktaki kullanımlarının genişletilebilmesi adına farkındalık sağlamak amaçlanmıştır.

\subsection{Mimarlık Eğitiminde Sesli Asistanlar}

Bilgisayar teknolojilerinin sağladığı tasarımda çeşitlilik ve farklılık sayesinde mimarlık eğitimi ve uygulamalarında hızlı bir değişim süreci başlamıştır. Dijital yazılımların katkıları tasarımı daha hızlı ve verimli bir süreç haline getirmiş, bu nedenle tasarım eğitimi veren kurumlarda bilgisayar kullanımı zorunlu bir hâl almıştır [7].

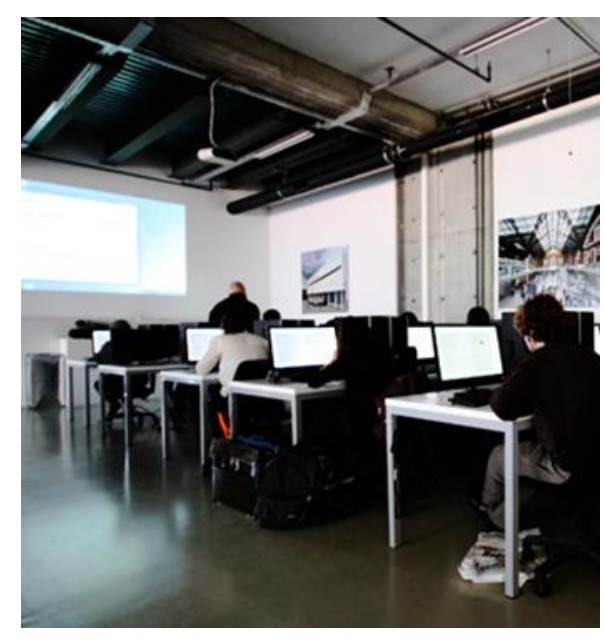

Şekil 4. Bilgisayar destekli mimarlık eğitimi [8].

Fakat Yurtsever'e göre (2011), mimarlık eğitiminde bilgisayar destekli programlar mimari tasarımda öğrenciye çok farklı seçenekler sunmasına rağmen bazı nedenlerden dolayı kısıtlayıcı özelliklere de sahiptir [9]. Bu kısıtlayıcılık öğrencinin programın nasıl kullanıldığını bilmemesinden kaynaklanmaktadır. Mimarlık eğitimi veren birçok kurumun bu kısıtlayıcılık üzerine gelişen sorunları yasak getirerek çözme yoluna gittiğinden bahsedilmekte, ancak yapılması gerekenin programdan kaçmak yerine daha verimli şekilde kullanabilmenin yollarının araştırılması olduğu belirtilmektedir. Bahsi geçen programlar, bilinmesi gereken çok sayıda komut ile kullanılabilmeleri ve çoklu dil desteği sağlayamamaları gibi birtakım kısıtlayıcı özellikler içermektedir. Fakat Türkçe sesi algılayabilecek yazılımlarla desteklenen bir tasarım programı olduğu varsayılacak olursa bunun öğrencilerin bu programı daha rahat anlayıp 
kullanmalarına olanak sağlayacağı öngörülebilir. Ayrıca çoklu dil desteği sağlayacağı için komutları bilinmeyen programları kullanmada ortak sesli bir dil ortaya koyulabilir. Bunun yanında etkileşimde çeşitlilik artacağından dolayı tasarım derslerinde daha eğlenceli bir ders ortamı oluşabilir.

2015 yılında Fransız Eğitim Bakanlığı, ilkokul çocuklarına İngilizce öğretmek için bir sesli asistanın geliştirilmesi ile ilgili teklif çağrısı yapmıştır. Bu asistanın ileri seviyede dil bilgisine sahip olmayan öğretmenler için de bir yardımcı olacağı belirtilmiştir [10]. Canberk ve Mutlu (2016) ise, sesli asistanlar olan Siri, Cortana ve Google Now'u dil eğitimi için yapay zekâ bağlamında incelemişlerdir. Bu yardımcıların dil eğitimi için uygun araçlar olduğu ve dolayısıyla çalışmalarının daha kalitatif ve kantitatif çalışmalara kapı açabileceğini sonucuna varmışlardır [11]. Bilindiği üzere mimarlık fakültelerinde de teknik ve estetik kuralları olan bir çizim dili eğitimi verilmektedir. Bu açıdan bakıldığında dil eğitimine katkı sağlaması öngörülen sesli asistanların, mimarlıktaki çizim dilinin teknik kurallarının eğitimine de katkı sağlayabileceği ortadadir.

Bunlarla beraber yaşanan pandemi sürecinden dolayı zorunlu olarak gelişen karantina şartlarında uzaktan eğitim sisteminin, ses komutlarının dahil olduğu çoklu katılım olanağı sunabilecek çizim ve tasarım programlarının varlığıyla çok daha verimli bir platforma dönüşebileceği düşünülebilir. Ayrıca bu tarz bir programın, yukarıdaki örneklerde değinildiği gibi, bedensel engelli öğrencilere de, sağlayacağı rahat öğrenme avantajıyla birçok veriye erişim kolaylığı sağlayacağı öngörülmektedir.

\subsection{Mimari Tasarımda Sesli Asistanlar}

Eğitimini tamamlamış bir mimar teorik altyapısını oluşturmuş ve mimari bir eser ortaya koyabilmek adına tasarım aşamasına geçmiştir. Bu tasarım adımları genellikle bilgisayar destekli olarak dijital ortamda yapılmaktadır ve mimarlık alanında bu dijital tasarım, geniş yelpazeli süreçlerden geçmektedir. $\mathrm{Bu}$ süreçler, iki boyutlu çizimler, üç boyutlu modellemeler, animasyonlar, yapılmış tasarımın sanal ortamda deprem dayanımı modellemesi, aydınlatma ve 1s1 korunumu gibi performansların simüle edilmesi, metraj-keşif çıkarma gibi birçok dijital işlemi kapsamaktadır [12].

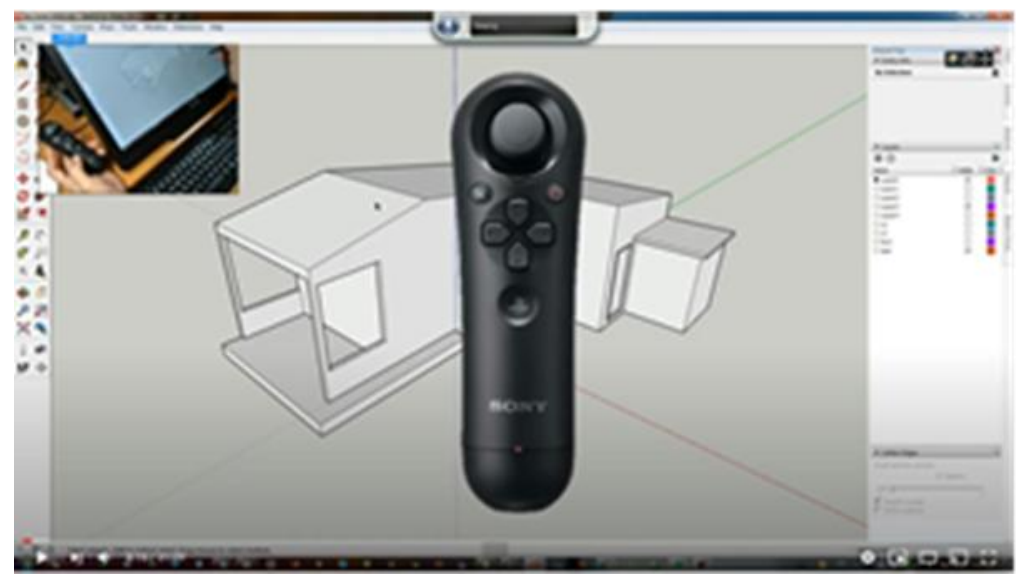

Şekil 5. 3B mimari modellemede sesli komut [13].

Video içerikleri paylaşılan bir platformda, bir kullanıcının mimari bir modelleme programına ses komutlarıyla çalışan bir yazılım entegre ettiği görülmüștür (Şekil 5). Bu uygulamada tasarım, klavye ve fareyle beraber ses komutları kullanılarak yapılmıştır. Ses komutlarının entegre edilmesiyle kullanıcının iş veriminin arttı̆̆ı gözlemlenmiştir. Mimari ürünün, uygulama 
aşamasına kadar birçok dijital süreçten geçtiği düşünüldüğünde, tüm bu işlemlerde kullanılmakta olan yazılımların tamamının kullanımını kolaylaştırmayı ve hızlandırmayı sağlayabilecek bir yeniliğin mimari ürünün ortaya çıkış sürecini daha verimli hale getireceği öngörülebilir.

\subsection{Mimari Sunumda Sesli Asistanlar}

Mimari proje sürecini tamamlamış bir mimarlık öğrencisi ya da profesyonel iş hayatında yer alan bir mimar, projesini jüriye ya da müşterisine (özel, kamu ya da şahsa ait bir kurum/firma) sunması gerekmektedir. Poster sunumlarında amaçlanan, bilgiyi kısa sürede karşı tarafa etkili ve anlaşılır bir şekilde kısa sürede aktarmaktır. Mimari sunum paftalarında da amaç, izleyiciyi proje hakkında bilgilendirmek, aynı zamanda ikna etmektir. Literatürde "grafik sunum" ya da "grafik pafta" ifadeleri ile de yer alan paftalar, projelerin tasarım sürecini anlatır. Sunumlarda, izleyicinin mekânı tam olarak algılayabilmesi, hissedebilmesi ve onaylaması hedeflenir [14]. Tasarımı yapılmış mimari ürünün uygulama aşamasına geçebilmesi için sunumun izleyicisi konumunda olan müşterisinin etkilenmesi amaçlanır. Bu nedenle mimari sunum, süreçteki önemli adımlardan biridir.

Saha araştırmasında TV üretimi yapan bir teknoloji firmasının ürünlerinden birinde ses komutlarını kullandığı görülmüştür (Şekil 6). Bu sayede kullanıcı, yayın akışı görselleri arasından yapacağı seçimi kumanda yerine sesli komutlarla gerçekleştirmektedir.

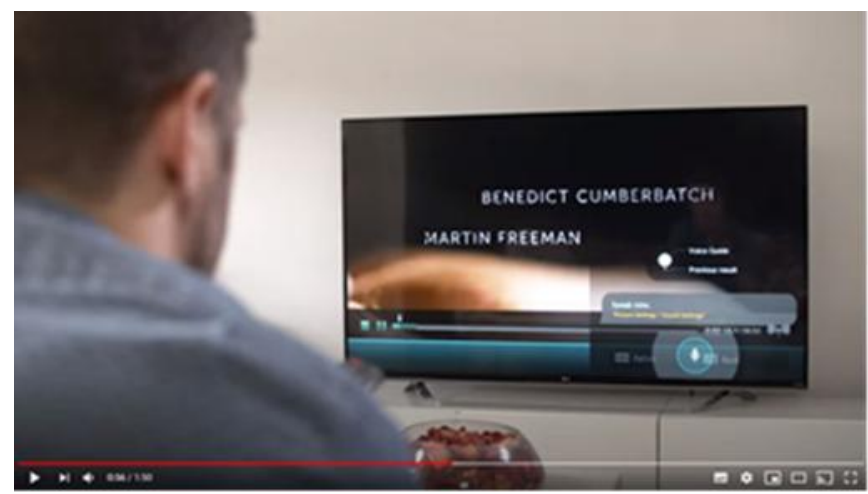

Şekil 6. Televizyonda sesli komut kullanımı [5].

Yayın akış görsellerinin de TV kanallarının potansiyel izleyicilerine yaptıkları kısa sunumlar oldukları düşünüldüğünde sesli komutların mimari sunumlarda da kullanılmasının süreci benzer şekilde dikkat çekici hale getirebileceği görülebilir. Bunlarla beraber mimari bir ürünün üretim aşamasından sonra kullanıcı kazanabilmesi için çoğunlukla pazarlanması gerekir. Pazarlamanın da bir sunum tekniği olduğu göz önünde bulundurulduğunda ve konu yukardaki örnekle ilişkilendirildiğinde, sesli komutların mimari sunum sürecine sağlayabileceği potansiyel faydalar incelemeye değerdir.

\subsection{Mimari Uygulama Süreçlerinde Sesli Asistanlar}

Tasarımı yapılmış bir mimari ürünün bir sonraki aşaması ise uygulamadır. Yapının büyüklügüne, türüne ve tekniğine göre çok karmaşık boyutlara ulaşabilen bu süreç, kendi içinde birçok alt dala ayrılmaktadır. İnşaat uygulama süreçlerinin içerdiği bina işletme, maliyet, iş ve bilgi yönetimi gibi alanlarda çoğunlukla bilgisayar destekli yazılımlardan faydalanılmaktadır [15]. Gelişmekte olan ülkeler, artan yapı talebine yanıt verebilmek için inşaat sektöründe teknolojik ilerlemelere ihtiyaç duymaktadır. Bu ülkelerde sıklıkla ulaşım, enerji santralleri, havalimanları, barajlar, köprüler, yerleşim alanları vb. projeler yapılması gerekir. Dolayısıyla bu projeler ülkelerin ekonomilerinde büyük pay sahibidir [16]. Bunlarla beraber bir projenin uygulaması birçok alt 
disiplinin birlikte çalıştığı bir süreçtir. Bilgisayar destekli yazılımlar, insan iş gücü ya da çeşitli büyüklükte iş makineleri bu sürece hizmet eder. Bu nedenle sesli komutların kullanımı daha önce bahsedilen dijital süreçler gibi uygulama sürecine de verim ve hız kazandırabilir. Saha araştırmasında bir otomobil modelinde aracın bazı komutları ses ile algıladığı gözlemlenmiştir (Şekil 7). Aynı sistemin benzer şekilde inşaat uygulamalarında kullanılan iş makinelerine entegre edilmesi durumunda hassas ölçümler, beton dökümü, kule vinç hareketleri gibi hata olasılığının kötü sonuçlara neden olduğu işlemlerin aplikasyonlarını daha verimli ve güvenli hale getireceği düşünülmektedir.

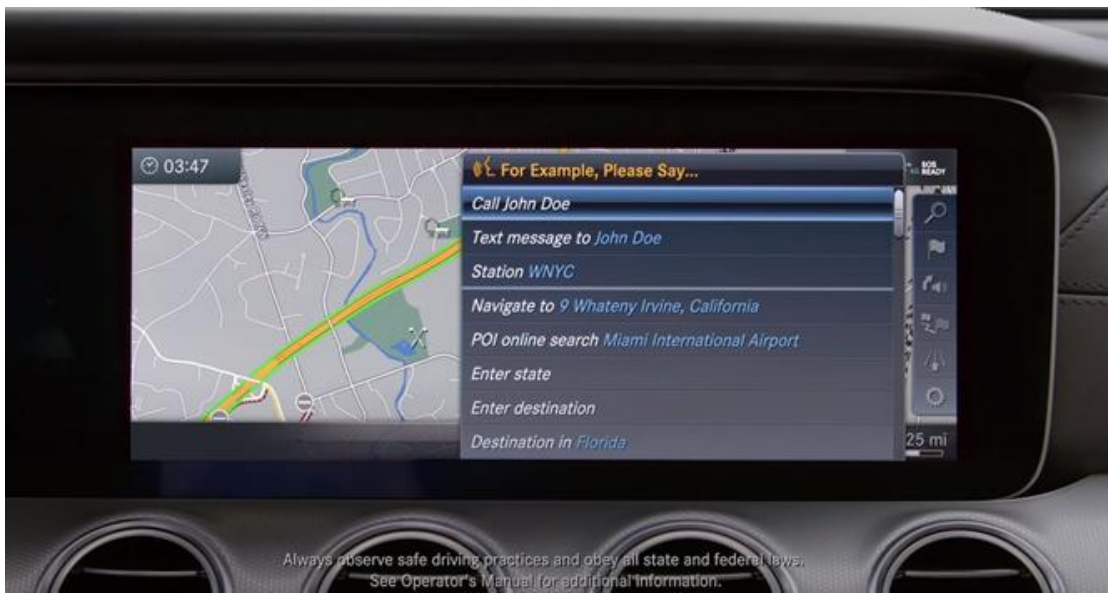

Şekil 7. Mercedes-Benz marka bir otomobilde sesli komut kullanımı [3].

Ayrıca bilindiği üzere uygulamanın dijital disiplinleri olan şantiye ofislerinde arşivleme ve hakediş gibi çeşitli süreçler gerçekleştirilmektedir. Sesli asistanlar sayesinde bu süreçlerin, "2.2. Mimari Tasarımda Sesli Asistanlar" başlığı altında değinilen kazanımlar ile daha verimli hale gelebileceği düşünülmektedir.

\subsection{Mimari Ürünün Kullanımında Sesli Asistanlar}

Mimari ürünün son aşaması ve amacı kullanıcılarına yaşattığı mekânsal deneyimdir. Mekânsal deneyim ise estetikten proporsiyona, malzemeden 1ş1ğa kadar birçok parametreye bağlıdır. Mimari bir hacimde mekânın en, boy ve yüksekliğinin, aldığı 1şık miktarının, duvar ve kaplama renginin, odaları arasındaki mesafelerin ve hatta ortam kokusunun dahi birer parametre olarak mekânsal deneyime ve kullanım kalitesine etki ettiği bilinmektedir.

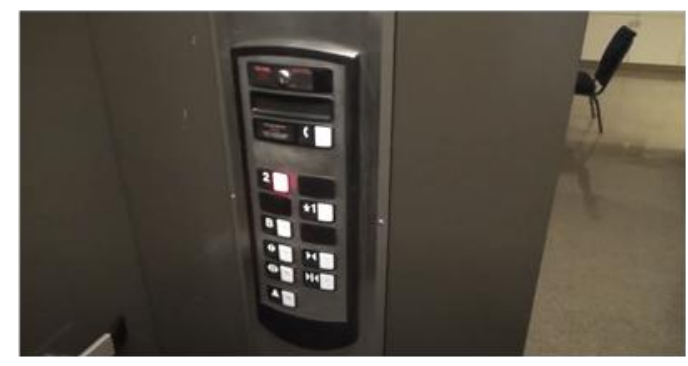

(a)

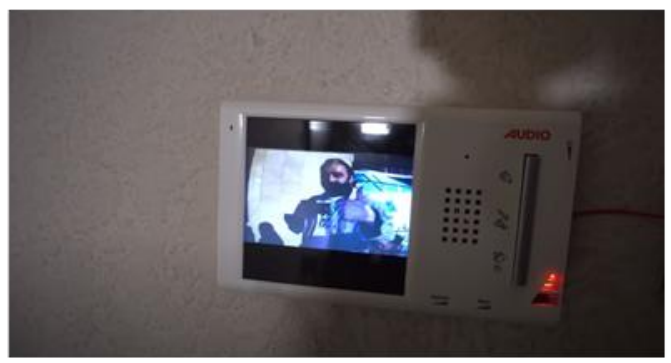

(b)

Şekil 8. a) Sesli komut kullanılan asansör örneği [18]. b) Sesli komut özellikli megafon [19]. 
Bu mekânsal deneyime sesin entegresi ise örneklenen parametrelerden değerleri değiştirilebilir nitelikte olanlara etki edebilir ve böylelikle kullanıcı deneyimini zenginleştirebilir. Örneğin lambayı açmak için yürümek yerine ses kullanıldığında yaşam alanıyla farklı bir etkileşime girilmiş olur. Nitekim halihazırda mekân içerisinde 1şık kontrolü ve elektrikli ev aletlerinin ses ile kontrolü mevcuttur [17]. Bunun yanında ortak kullanım alanlarında bulunan asansör ve dış kapının da sesli komutlarla kullanılabildiği gözlemlenmiştir (Şekil 8a, 8b). Yaşanan pandemi sürecinin gerektirdiği hijyen kuralları, çevredeki nesnelerle yapılan dokunmatik etkileşimi minimuma indirgemeyi gerektirmektedir. $\mathrm{Bu}$ detaya odaklanıldı̆̆ında, sesli etkileşim yöntemlerinin önemi daha çok ortaya çıkmaktadır.

Ayrıca mimari ürün içerisinde ses komutları kullanılarak yapılan tüm bu etkileşimlerin konforu ve mekânsal deneyim kalitesini artırdığı görülmektedir. Gelecekte bu teknoloji geliştikçe, örneğin kayar bir duvarın yeri ya da bir kaplamanın rengi sesle değiştirilebildiğinde hâli hazırdaki mekânsal deneyim farklı bir boyuta taşınmış olacaktır.

\section{Sonuçlar}

Mimarlık, gelişen ve değişen insanoğlunun günlük hayatına hızla uyum sağlaması gereken bir bilim ve sanat sürecidir. Teknolojinin gelişimi ve her geçen gün sağladığı yeni olanaklar ise ortadadır. Mekânsal ihtiyaçlarımızın hızı ve konforu ise bu olanakların ve gelişimin gerisinde kalma lüksüne sahip değildir.

$\mathrm{Bu}$ makalede, çeşitli örnekler eşliğinde sesli asistanlar mimarlık bağlamında incelenmiştir ve sesli asistanların mimarlığa katkısı özelinde çeşitli öngörülerde bulunulmuştur.

İncelenen örnekler ve bu örnekler üzerinden yapılan öngörüler, sesli asistanların mimari ürünün oluşum ve kullanma süreçlerini daha hızlı ve verimli hale getireceğini ortaya koymaktadır. Bu nedenle sesli asistanlar, mimarlık alanına katkı sağlayan her disiplin tarafından incelenmeli ve asistanların sağlayacağı kolaylıklardan faydalanılmalıdır.

Özellikle dokunmaya dayalı etkileşimin azaltılmasının hedeflendiği COVID-19 pandemi sürecinde sesli asistan sistemlerinin günlük hayatın içinde yaygınlaşmasının önemi daha çok ortaya çıkmıştır. Yaşanılan ortamların büyük çoğunlukla mimari yapılar olduğu dikkate alındığında sesli asistanların mimarlık alanındaki kullanımı konusu bu probleme bir çözümleme olarak da geliştirilebilir.

İncelemelerde mimarlığın, sesli asistanların kullanımı açısından oldukça boş bir araştırma alanına sahip olduğu görülmüştür. Katkı potansiyelleri öngörülerle açıklanmaya çalışılan alan, diğer araştırmacılar tarafından bilimsel/teknik çalışmalarla doldurulmalı ve teknolojinin desteğiyle güncellenmelidir.

\section{Kaynaklar}

[1]. Sanal Asistan, https://tr.wikipedia.org/wiki/Sanal_asistan, (Erişim Tarihi: 2020).

[2]. Canlı Pixel, M\&B 2 Bannerlord VoiceAttack Türkçe Sesli Komut Rehberi [Video dosyas1], Erişim adresi: https://www.youtube.com/watch?v=hQfTh-qWg4s, (Erişim Tarihi: 2020).

[3]. Mercedes-Benz USA, How to Use Mercedes-Benz Voice Control [Video dosyas1], Erişim adresi: https://www.youtube.com/watch?v=1wTf33uGxzw, (Erişim Tarihi: 2020).

[4]. Erçel, S., NANDS Assistant (Ses ile Bilgisayar Yönetmek) [Video dosyası], Erişim adresi: https://www.youtube.com/watch?v=kLLypwkij1c, (Erişim Tarihi: 2020). 
[5]. LGAustralia, How To Use Voice Recognition On Your LG Smart TV [Video dosyas1], Erişim adresi: https://www.youtube.com/watch?v=SHEl5xzrhkA, (Erişim Tarihi: 2020).

[6]. Yazıcıoğlu, F., Bütünsel Mimarlık Eğitiminin Bir Bileşeni Olarak Mimarlıkta Teknoloji Eğitimi İçin Model Önerisi, İstanbul Teknik Üniversitesi Fen Bilimleri Enstitüsü Mimarlık Anabilim Dalı, İstanbul, 2013.

[7]. Mıhlayanlar, E., Tachir, G., Mimarlık Eğitiminde Bilgisayar Destekli Tasarımdan Bina Enformasyonuna, Artium, 2019, 17(2): 167-179.

[8]. Eğitim Ortamı, https://www.bilgi.edu.tr/tr/akademik/mimarlik-fakultesi/egitim-ortami/, (Erişim Tarihi: 2020).

[9]. Yurtsever, B., Mimarlık Eğitiminde Eleştirel Düşünme Becerisinin Rolü: Birinci Yıl Tasarım Eğitimi, İstanbul Teknik Üniversitesi Fen bilimleri Enstitüsü Mimarlık Anabilim Dalı, İstanbul, 2011.

[10]. French Ministry of Education to Bring Voice Assistants into the Classroom, https://voicebot.ai/2019/09/27/french-ministry-of-education-to-bring-voice-assistants-intothe-classroom/, (Erişim Tarihi: 2020).

[11]. Canberk, N., Mutlu, N., Sayısal Gelecekte Yeni Adım: Akıllı Kişisel Yardımcılar, Açıköğretim Uygulamaları ve Araştırmaları Dergisi, 2016, 2(1): 114-129.

[12]. Yıldırım, T., Özen, A., İnan, N., Uzaktan Mimari Tasarım Eğitiminde İnternet Teknolojilerinin Kullanımı, Bilişim Teknolojileri Dergisi, 2008, 1(2), 37-45.

[13]. Rootaman, Voice Command Testing For Sketchup [Video dosyas1]. Erişim adresi: https://www.youtube.com/watch?v=LbwgmW2L9H4, (Erişim Tarihi: 2020).

[14]. Kürşad, D., Mimari Sunum Paftalarında Görsel Tasarım İlkelerinin Uygulanması Üzerine Öneriler, Atatürk Üniversitesi Güzel Sanatlar Enstitüsü Dergisi, 2020, 26(44), 211-221.

[15]. Keleş, A., Kaya Keleş, M., İnşaat Sektöründe Kullanımı Artan Bilgisayar Yazılımları ve Bilgi Teknolojilerinin İrdelenmesi, El-Cezeri Journal of Science and Engineering, 2018, 5 (2), 610-617.

[16]. Pamuk, R., Kuruoğlu, M., İnşaat Sektöründe Sürdürülebilirlik Ve Bina İnşaatlarında Evrensel Uygulama Örnekleri, Beykent Üniversitesi Fen ve Mühendislik Bilimleri Dergisi, 2016, 9(1), 161-177.

[17]. Bergan, S., Alexa vs Jarvis Voice Control [Video dosyas1], Erişim adresi: https://www.youtube.com/watch?v=fUBX9cmMLu4, (Erişim Tarihi: 2020).

[18]. STL Elevators, Voice Controlled Elevator [Video dosyas1], Erişim adresi: https://www.youtube.com/watch?v=kcj-_s0Ge3E, (Erişim Tarihi: 2020).

[19]. Özuygur, T., Ses Komutu İle Kap1 Açmak [Video dosyas1], Erişim adresi: https://www.youtube.com/watch?v=LWh619I4a4o, (Erişim Tarihi: 2020). 